\title{
Saberes e práticas de cuidado em saúde da população do campo:
}

revisão integrativa da literatura

Bianca Rückert(a)

Daisy Moreira Cunha ${ }^{(b)}$

Celina Maria Modena ${ }^{(c)}$

Rückert B, Cunha DM, Modena CM. Healthcare knowledge and practices of the rural population: an integrative literature review. Interface (Botucatu). 2018; 22(66):903-14.

This paper presents the results of an integrative literature review about the healthcare knowledge and practices of the Brazilian rural population. The analyzed sample had 16 papers found in the Brazilian Health Virtual Library (BVS), the Scientific Electronic Library Online (SciELO) and the Observatory of the Brazilian Policy for Comprehensive Health of Countryside, Forest and Water Populations (OBTEIA) databases with no restriction regarding the year of publication. Examination of literature evidenced the diversity of healthcare practices, which involve medicinal plants, beliefs and religiosity, a healthy diet, social support and prevention, among other aspects. It was found that cultural context, economic issues and difficult access to health services favor the development of these practices and that these draw upon many types of knowledge and wisdoms. It is worth noting the need to value this knowledge and its integration with the conventional healthcare system background.

Keywords: Health knowledge, attitudes, practice. Health care. Knowledge. Rural health. Literature review.
Este artigo apresenta os resultados de uma revisão integrativa de literatura sobre os saberes e as práticas de cuidado em saúde da população do campo em território brasileiro. Foram analisados 16 artigos, a partir de seleção nas bases de dados Biblioteca Virtual de Saúde (BVS), SciELO e Observatório da Política Nacional de Saúde Integral das Populações do Campo, Floresta e Águas (Obteia), sem recorte temporal. A análise da literatura evidenciou a diversidade das práticas de cuidado, que envolvem plantas medicinais, crenças e religiosidade, alimentação saudável, apoio social, prevenção, entre outras. Verificouse que o contexto cultural e a dificuldade econômica e de acesso aos serviços de saúde favorecem o desenvolvimento dessas práticas, e que estas se baseiam em inúmeros saberes. Ressalta-se a necessidade de maior valorização desses saberes, bem como a sua integração com os saberes do sistema convencional de saúde.

Palavras-chave: Conhecimentos, atitudes e prática em saúde. Cuidado em saúde. Saberes. Saúde da população rural. Revisão da literatura.

\footnotetext{
(a, c) Grupo de pesquisa em Políticas Públicas e Direitos Humanos em Saúde e Saneamento, Instituto René Rachou, Fundação Oswaldo Cruz. Avenida Augusto de Lima, 1715. Belo Horizonte, MG, Brasil. 30190009.biaruckert@ yahoo.com.br; celina@ minas.fiocruz.br.

(b) Departamento de Administração Escolar, Faculdade de Educação, Universidade Federal de Minas Gerais. Belo Horizonte, MG, Brasil. daisycunhaufmg@ gmail.com.
} 


\section{Introdução}

Dados do Instituto Brasileiro de Geografia e Estatística (IBGE) revelam que, em 2010, a população brasileira era de 190.755.799 pessoas. Dessas, quase 30 milhões residiam em áreas rurais, representando $15,6 \%$ da população total ${ }^{1}$. Para o IBGE ${ }^{2}$, população rural é toda população que reside fora dos limites das áreas urbanas. Este é um conceito que define o rural por antagonismo e eliminação às áreas urbanas e, por isso, é uma definição "eminentemente físico-geográfica e arbitrária, por não considerar as relações e processos econômicos e sociais que constituem esses espaços sociais." ${ }^{3}$ (p. 35).

Em contraposição, outros conceitos são utilizados para se referir às populações rurais, evidenciando a diversidade presente nesses territórios. Tratam-se das populações do campo, da floresta e das águas, que se caracterizam "por seus modos de vida, produção e reprodução social relacionados predominantemente com a terra."4 (p. 8). Em especial, a população do campo é identificada como aquela que se apoia nos saberes tradicionais e na relação com a natureza para produzir seu autossustento e comercializar o excedente da produção. Nessa perspectiva, consideram-se os "agricultores familiares, trabalhadores rurais assentados ou acampados e temporários que residam ou não no campo"4 (p. 8).

A diversidade desses territórios se faz presente também na multiplicidade das práticas populares de saúde, seja para se defrontar com o adoecimento, seja para fortalecer a saúde, por meio das: "plantas medicinais [...], sementes crioulas, rezas, benzimentos, erveiros, raizeiros, massagista, auriculoterapia, acupuntura, homeopatia, terapia comunitária, parteiras, [...] entre outros ${ }^{5 "}$ (p. 213).

Em que pese essa pluralidade, os dados sobre as condições de vida e saúde da população do campo revelam uma situação de iniquidade quando comparadas à população urbana. No campo, é maior a porcentagem de mortalidade infantil e insalubridade ${ }^{6}$. Do total de pessoas que vivem no campo, $25,5 \%$ enfrentam uma situação de extrema pobreza, $71 \%$ são negros e $26 \%$ são analfabetos ${ }^{7,8}$. Em relação à cobertura de saneamento, apenas $28,9 \%$ dos domicílios são ligados à rede de abastecimento de água potável com canalização interna ${ }^{7}$.

No tocante às condições de saúde, ainda permanecem doenças infectoparasitárias decorrentes da precária situação de saneamento. São frequentes as lesões por esforços repetitivos (LER), os distúrbios osteomusculares relacionados ao trabalho (Dort) e morbidades relacionadas à intoxicação por agrotóxicos e metais pesados. Tais aspectos revelam a existência de um perfil epidemiológico diferenciado para a população do campo 7,8 .

Somam-se a esses fatores as deficiências de acesso e qualidade dos serviços de saúde. Após mais de 25 anos de fundação do Sistema Único de Saúde (SUS), é importante reconhecer o " [...] caráter desintegrado, centralizado, curativo, urbano e não universal [...]" que marcam ainda hoje as políticas de saúde no campo9 $^{9}$ (p. 696).

De forma a assegurar o cumprimento dos princípios do SUS, políticas de equidade são construídas, visando "à garantia do acesso resolutivo e com qualidade para as populações em situações de vulnerabilidade." ${ }^{5}$ (p. 11). Uma dessas é a Política Nacional de Saúde Integral das Populações do Campo, da Floresta e das Águas (PNSIPCFA), que tem o objetivo de promover "o acesso aos serviços de saúde, a redução de riscos e agravos à saúde decorrente do processo de trabalho e das tecnologias agrícolas e a melhoria dos indicadores de saúde e da qualidade de vida." ${ }^{4}$ (p. 20).

Dentre os objetivos da PNSIPCFA, destaca-se o de "reconhecer e valorizar os saberes e as práticas tradicionais de saúde das populações do campo e da floresta, respeitando suas especificidades." ${ }^{4}$ (p. 24). Tais práticas são concebidas por meio da apreensão e leitura do mundo pelas camadas populares, de suas heranças culturais, de suas vivências e de suas condições de vida e trazem importantes contribuições para a promoção da autonomia e para a constituição de sujeitos agentes de suas ações de saúde ${ }^{10}$.

Vasconcelos ${ }^{11}$ salienta o aporte da participação popular na reorientação das práticas de atenção à saúde, na perspectiva de se construir um sistema mais integral, eficaz e orientado às especificidades das populações. De acordo com o autor, "muitas experiências comunitárias vêm demonstrando a forte potencialidade das ações de saúde na reorientação da vida social"11 (p. 287). Para tanto, faz-se necessário redirecionar o modo como o sistema de saúde relaciona-se com os usuários, de forma a ouvir e considerar os saberes de saúde dessas populações. 
Nesse sentido, um dos eixos do plano operativo da PNSIPCFA consiste em desenvolver ações de educação permanente e educação popular em saúde. Estas devem ser desenvolvidas com o intuito de proporcionar a integração de saberes e práticas de cuidado das populações do campo, da floresta e das águas com os saberes e as práticas dos serviços de saúde 4 .

A partir desses pressupostos, este estudo teve como objetivo identificar e analisar a produção científica sobre os saberes e as práticas de cuidado em saúde adotadas pela população do campo em território brasileiro, para o qual se realizou revisão integrativa da literatura em bases nacionais.

\section{Aspectos metodológicos}

Neste artigo, foi utilizada a revisão integrativa da literatura, considerando-se o seu propósito de sistematizar resultados de pesquisas acerca de um assunto específico. Nesta sistematização, destaca-se o que já foi construído acerca desse assunto, bem como as lacunas do conhecimento científico, que requerem novas pesquisas. Assim, a partir de estudos prévios, podem-se traçar conclusões gerais sobre uma determinada área de pesquisa ${ }^{12}$.

Souza et al. ${ }^{13}$ consideram a revisão integrativa como o procedimento de revisão bibliográfica mais abrangente, por proporcionar a incorporação de pesquisas que utilizem os mais variados métodos, conjugar dados da literatura teórica e empírica e englobar uma ampla variedade de finalidades, que incluem desde a "definição de conceitos, revisão de teorias e evidências, e análise de problemas metodológicos de um tópico particular"13 (p. 103). Ainda de acordo com as autoras:

Diante da necessidade de assegurar uma prática assistencial embasada em evidências científicas, a revisão integrativa tem sido apontada como uma ferramenta ímpar no campo da saúde, pois sintetiza as pesquisas disponíveis sobre determinada temática e direciona a prática fundamentando-se em conhecimento científico. ${ }^{13}$ (p. 105)

Para produção da revisão integrativa, seguiram-se os seguintes passos: delimitação do objetivo e das perguntas de pesquisa; realização da busca de pesquisas em bases de dados, de forma a atender aos critérios de inclusão e exclusão definidos antecipadamente; coleta de dados e análise dos estudos incluídos; e discussão e apresentação dos resultados ${ }^{12,13}$.

Para orientar a revisão integrativa, construíram-se as seguintes questões: Quais práticas são adotadas pela população do campo no cuidado em saúde familiar e comunitária? Como se dão os processos de aprendizagem dessas práticas?

A seleção dos artigos foi realizada por meio de consulta aos sites da Biblioteca Virtual de Saúde (BVS) Brasil, Scientific Eletronic Library Online (SciELO) e do Observatório da Política Nacional de Saúde Integral das Populações do Campo, Floresta e Águas (Obteia).

A partir de pesquisa no site Descritores em Ciências da Saúde, foram escolhidos os descritores "Saúde da população rural" e "Conhecimentos, atitudes e prática em saúde". Considerando-se o objeto do estudo, também foram utilizados os termos "Saúde da população do campo", "Saberes" e "Cuidado". Realizaram-se seis cruzamentos: "Saúde da população rural" and "Conhecimentos, atitudes e prática em saúde"; "Saúde da população rural" and "Saberes"; "Saúde da população rural" and "Cuidado", "Saúde da população do campo" and "Conhecimentos, atitudes e prática em saúde"; "Saúde da população do campo" and "Saberes"; e "Saúde da população do campo" and "Cuidado", respectivamente. Na consulta à SciELO foram utilizados os filtros "Brasil como assunto" e "Brasil como país de filiação", separadamente e para cada cruzamento, totalizando 12 buscas. Na consulta ao site do Obteia, não foram realizados cruzamentos, apenas busca a partir das palavraschaves "Conhecimentos, atitudes e prática em saúde", "Saberes" e "Cuidado". Não foi realizado recorte temporal. A busca resultou em 677 trabalhos localizados. O acesso aos bancos de dados foi realizado no período entre janeiro e julho de 2017.

Em seguida, realizou-se a exclusão dos trabalhos repetidos e ajuste do material aos objetivos do estudo. Para isso, foram utilizados os seguintes critérios de inclusão: ser artigo científico; estar 
disponível na íntegra; e tratar sobre saberes e práticas de cuidado em saúde desenvolvidas pela população do campo em território brasileiro. Nesse sentido, excluíram-se dissertações e teses, artigos não disponíveis na íntegra e estudos que não contemplassem o objetivo proposto.

Para a seleção dos trabalhos, realizou-se uma leitura fundamentada dos títulos e resumos de cada estudo e, em caso de dúvidas relativas ao assunto, procedia-se à leitura parcial ou integral do texto. Essa seleção resultou em 16 trabalhos, que integraram o corpus de análise da revisão integrativa. $\mathrm{Na}$ Tabela 1 é possível visualizar a amostra inicial de cada busca, bem como o número de publicações excluídas de acordo com os critérios adotados.

Tabela 1. Número de publicações excluídas por critérios na revisão integrativa

\begin{tabular}{|c|c|c|c|c|c|}
\hline & BVS* & BVS** & Scielo & Observatório PNSIPCFA & Total \\
\hline Amostra inicial & 267 & 308 & 85 & 17 & 677 \\
\hline $\begin{array}{l}\text { Trabalhos excluídos por não se referirem ao objeto } \\
\text { da revisão }\end{array}$ & 149 & 147 & 10 & 6 & 312 \\
\hline Trabalhos repetidos & 97 & 145 & 69 & 6 & 317 \\
\hline $\begin{array}{l}\text { Trabalhos excluídos por investigarem outras } \\
\text { populações rurais }\end{array}$ & 8 & 7 & 0 & 1 & 16 \\
\hline Dissertações ou teses & 3 & 0 & 0 & 2 & 5 \\
\hline $\begin{array}{l}\text { Trabalhos excluídos por não diferenciarem população } \\
\text { do campo de população urbana }\end{array}$ & 3 & 0 & 0 & 0 & 3 \\
\hline $\begin{array}{l}\text { Trabalho excluído por se referirem à população do } \\
\text { campo de outros países }\end{array}$ & 0 & 2 & 6 & 0 & 8 \\
\hline Amostra final & 7 & 7 & 0 & 2 & 16 \\
\hline
\end{tabular}

* Filtro Brasil como assunto; ** Filtro Brasil como país de filiação

Uma caracterização geral dos artigos foi apresentada, considerando-se o objeto de investigação, o público participante e a metodologia empregada. Os resultados foram apresentados de forma descritiva e reunidos em três eixos temáticos: Práticas de saúde da população do campo no cuidado comunitário e familiar; Aspectos socioculturais das práticas de cuidado em saúde da população do campo; e Produção e mobilização dos saberes de cuidado em saúde da população do campo.

\section{Resultados}

\section{Breve caracterização dos estudos sobre saberes e práticas de cuidado em saúde da população do campo}

Levando em consideração os objetivos da revisão integrativa e os critérios de inclusão e exclusão dos trabalhos, foram identificados e analisados 16 artigos. A maioria refere-se às práticas de cuidado voltadas para atender uma ampla gama de necessidades de saúde, passíveis de cuidados no âmbito familiar e comunitário. Um deles, entretanto, aborda práticas de parteiras tradicionais durante o trabalho de parto e o nascimento ${ }^{14}$, dois textos abordam o cuidado às pessoas com sofrimento mental ou usuárias de drogas ${ }^{15,16}$, e outros dois tratam de saberes e práticas de doenças específicas, como é o caso do estudo de Vilella et al. ${ }^{17}$, relacionado à doença de Chagas, e o estudo de Zilmer et al. ${ }^{18}$, referente ao adoecimento por câncer.

Em relação ao público investigado, seis trabalhos ${ }^{15,19-23}$ tratam de populações assentadas da reforma agrária, dos quais três ${ }^{15,22,23}$ referem-se a integrantes do Movimento dos Trabalhadores Rurais Sem-Terra (MST). Três artigos ${ }^{24-26}$ tratam de mulheres agricultoras, sendo $u m^{26}$ sobre mulheres do Movimento de 
Mulheres Camponesas (MMC). Dois estudos abordam população quilombola ${ }^{27,28}$ e um se reporta a parteiras tradicionais ${ }^{14}$. Quatro pesquisas ${ }^{16-18,29}$ abordam população do campo sem distinção.

No que tange aos aspectos metodológicos, apenas um artigo ${ }^{17}$ caracteriza-se como pesquisa quantitativa, um estudo ${ }^{27}$ consistiu em uma pesquisa de caráter quanti-qualitativo e os demais consistem em pesquisa qualitativa. Estes se ancoraram em diversas propostas metodológicas, como estudo exploratório descritivo, etnografia, história oral e educação popular como método de análise.

\section{Práticas de saúde da população do campo no cuidado comunitário e familiar}

Entre as práticas de cuidado adotadas pela população do campo, o uso e preparo de remédios caseiros à base de plantas medicinais foi a mais citada na literatura ${ }^{14,18-27,29}$. Observa-se que esse uso, em especial, o consumo de chás, é uma prática incorporada no cotidiano das famílias camponesas ${ }^{19}$. A maior parte delas cultiva plantas medicinais nos próprios quintais, configurando-as como um patrimônio tradicional da comunidade ${ }^{20,29}$. Mas, ainda que se trate de uma prática disseminada, a literatura aponta para a existência de pessoas ou grupos de referência na comunidade para o preparo de remédios caseiros $^{22,24,27}$. O estudo de Lima et al. ${ }^{24}$, por exemplo, evidenciou que o trabalho de um grupo de mulheres agricultoras no Rio Grande do Sul envolve o cultivo e a coleta das plantas, a triagem, a fabricação dos produtos medicinais e a estocagem de plantas e remédios para outras estações.

De acordo com a literatura consultada, as plantas medicinais são utilizadas para o tratamento de diversos comprometimentos. Além do uso de espécies nativas, ressalta-se a importância das espécies exóticas na diversificação de terapias e ampliação do espectro de doenças tratadas pela comunidade ${ }^{29}$.

Em alguns momentos, as práticas de cuidado vêm acompanhadas de crenças, pois é preciso acreditar nos efeitos do remédio para seu resultado benéfico ${ }^{23,27}$. Em outros momentos, os ritos religiosos, a devoção a santos e as rezas são importantes na melhoria da saúde de modo geral ${ }^{20}$, na prevenção e tratamento de picadas de cobras ${ }^{21}$, no cuidado aos portadores de transtornos mentais severos ${ }^{16} \mathrm{e}$ às pessoas com câncer ${ }^{18}$, ou mesmo no momento do parto e nascimento ${ }^{14}$. Conforme Zilmer et al. ${ }^{18}$, a fé parece cumprir importante papel na superação das dificuldades vivenciadas diante do cuidado, bem como na potencialização da terapêutica.

Wunsch et al. ${ }^{19}$ destacam uma série de cuidados e crenças populares de famílias assentadas, que incluem o ato de se benzer antes do sol sair, considerar o calendário lunar para desenvolver certas práticas de cuidado, dispor o calçados lado a lado, usar sal para tirar olho gordo, evitar varrer a sujeira da casa para fora após anoitecer, entre outras.

Nos cuidados relacionados a mordidas de cobras, as crenças consistem em um importante recurso de saúde, tanto para a prevenção quanto para evitar os efeitos do envenenamento. Em caso de mordidas, por exemplo, deve-se evitar mencionar as palavras "picada", "mordida" e "cobra" ou nomear a espécie que causou o ferimento, pois os efeitos do veneno podem aumentar. Também se deve evitar receber visitas, exceto de familiares diretos. Foram registrados ainda encantos, como colocar uma cobra coral viva em uma garrafa de conhaque e beber o líquido, ou manter objetos de origem vegetal, animal ou mineral na carteira como amuletos, para as cobras manterem distância ${ }^{21}$.

Os cuidados com alimentação, por sua vez, envolvem desde a alimentação diversificada, a introdução de plantas medicinais, verduras e frutas caracterizadas como benéficas na alimentação, a redução de açúcar, sódio e gordura, e a preferência por alimentos de tradição familiar ${ }^{18,20,23-25}$. Alguns estudos enfatizam a importância do consumo de alimentos sem agrotóxicos e sem transgênicos ${ }^{19,22-24}$. Ricardo e $\operatorname{Stotz}^{23}$ tecem observações sobre o sentido da alimentação para agentes de cura de um assentamento do MST no estado do Rio de Janeiro. Para eles, os alimentos podem ser considerados fortes ou fracos, frescos, reimosos e quentes ou frios. Na roça, por exemplo, em contraposição com a cidade, os alimentos são mais fortes e frescos.

Ações de prevenção em saúde foram relatadas nos estudos de Wunsch et al. ${ }^{19} \mathrm{e}$ Cavalvante e Nogueira ${ }^{22}$. O primeiro estudo descreve ações de prevenção a acidentes de trabalho, como o uso de calçados adequados para andar no mato e de roupas apropriadas para exposição ao sol e ao calor ${ }^{19}$. Já o segundo trabalho aborda a ênfase nas ações de promoção como resultado de uma compreensão ampliada do processo saúde-doença, que perpassa por sua determinação social22. 
Outras práticas de cuidado compreendem o uso da terapia floral, da radiestesia, do passe espiritual, do reiki ${ }^{15}$ e da acupuntura ${ }^{25}$. Essas e as demais práticas, na maioria das vezes, vêm acompanhadas de uma atitude de zelo e solicitude ${ }^{18}$ e de um momento de diálogo com as próprias mulheres que participam dos grupos ou com as pessoas que recebem cuidados. Esse diálogo é atravessado por afeição, solidariedade, respeito e escuta ativa. Quem cuida também é cuidado, em uma relação mútua. Por outro lado, possibilita a construção de um olhar crítico sobre o processo saúde-doença, a socialização de conhecimentos e o fortalecimento das lutas ${ }^{20,23,26}$.

Assim, nas práticas analisadas, percebe-se o que Pinheiro ${ }^{30}$ reconhece como atitude interativa do cuidado, "que inclui o envolvimento e o relacionamento entre as partes, compreendendo o acolhimento como escuta do sujeito, respeito pelo seu sofrimento e história de vida" (p. 113). Nessa perspectiva, o cuidado se apresenta como possibilidade de aproximação das ações de saúde aos projetos de felicidade humana ${ }^{31}$.

Todavia, uma prática de cuidado não se desenvolve isoladamente, mas de forma integrada ou simultânea a outras práticas. Assim, o uso de plantas medicinais é articulado, por exemplo, às crenças religiosas e espirituais, à alimentação saudável e a outras recomendações, passando, inclusive, pelas práticas oferecidas pelos serviços públicos de saúde $20,26,27$.

Com relação às práticas de cuidado das parteiras tradicionais, a literatura registra uma conduta de mínima intervenção durante o trabalho de parto. Tal postura, muitas vezes, corresponde a não fazer nada e apenas esperar pacientemente, contribuir para alívio das dores e gerar as condições para as parturientes sentirem-se acolhidas e seguras. Desse modo, buscam resguardar a integridade da parturiente e evitar procedimentos invasivos que gerem vivências negativas do parto ${ }^{14}$.

Em se tratando dos cuidados relacionados à prevenção da doença de Chagas, o estudo de Villela et al. ${ }^{17}$ descreve a utilização de práticas como limpar a casa para evitar a presença do inseto-vetor da doença; borrifar inseticida no domicílio; evitar amontoados dentro de casa; limpar galinheiros; vistoriar cômodos, colchão e cama; e rebocar frestas na parede. Os autores ressaltam a ineficácia das práticas de higiene e limpeza, mas reconhecem a validade das demais práticas.

\section{Aspectos socioculturais das práticas de cuidado em saúde da população do campo}

A proximidade das práticas populares de cuidado, em especial o uso de plantas medicinais, às concepções e valores dos camponeses contribui na adesão à terapêutica, além de possibilitar maior participação dos sujeitos no próprio tratamento ${ }^{24}$. A literatura ressalta a importância dessas práticas por seu valor cultural, afirmando que estas contêm um significado concreto na vida das pessoas e, por isso, devem ser consideradas em discussões sobre saúde pública, saneamento e Medicina tradicional ${ }^{21}$. Nessa perspectiva, Ricardo e Stotz ${ }^{23}$ atribuem duas funções às práticas: "permitem a cura de doenças e a definição e atribuição de formas culturalmente reconhecíveis aos diversos tipos de doenças" 23 (p. 441).

O uso de recursos terapêuticos naturais também foi enfatizado pela literatura, atribuindo-se essa preferência à relação diferenciada que o camponês estabelece com a natureza. Além de serem mais acessíveis, tais recursos são considerados melhores que os produzidos por laboratórios químicos, com destaque para os medicamentos sintéticos e os agrotóxicos, que prejudicam o equilíbrio natural do organismo humano e o meio ambiente ${ }^{18,22-24}$. Essa perspectiva também foi observada no ofício das parteiras tradicionais, no qual a postura de mínima intervenção relaciona-se com o respeito ao tempo próprio da natureza humana ${ }^{14}$.

Tal perspectiva remete-nos à noção de saúde como dimensão normativa de Canguilhem, para a qual a Medicina apresenta função espectadora, ao respeitar a sabedoria que advém da natureza e contribuir no restabelecimento da dimensão normativa do ser. Do contrário, para uma ideia de que o organismo doente é um objeto passivo e dócil às manipulações, requer-se uma Medicina ativa ${ }^{32,33}$.

Diversos autores ressaltaram as dificuldades de acesso aos serviços de saúde e sua baixa resolutividade como fatores que favorecem o uso das práticas populares de cuidado. Tais dificuldades de acesso são sentidas nas distâncias entre as comunidades e os serviços de saúde, na escassez de transporte público e na insuficiência de profissionais de saúde $14,16,19,23,24,27$. Em alguns casos, pode estar 
relacionada à falta de investimentos públicos, dada a situação de irregularidade do território, como é o caso de algumas comunidades quilombolas ${ }^{27}$.

Além das dificuldades mencionadas, a literatura relata insatisfação com os serviços de saúde, por não atenderem às especificidades da população do $\operatorname{campo}^{16}$ e por ter baixa ou nenhuma integração entre os serviços e as práticas populares de cuidado ${ }^{22,27}$. Em contraposição, uma maior oferta da assistência pelos serviços públicos de saúde, bem como a diminuição da incidência de algumas doenças, pode acarretar na perda de saberes de saúde. Este é o caso dos saberes relacionados a picadas de cobras ${ }^{21}$, bem como dos saberes de prevenção à doença de Chagas ${ }^{17}$, nas respectivas comunidades investigadas.

Por outro lado, evidenciou-se que as práticas de cuidado propiciam proteção diante das adversidades vividas no campo por meio da produção agroecológica para consumo próprio, da autossustentação e das crenças e superstições ${ }^{19}$. Para Wunsch et al. ${ }^{19}$ (p. 537), "a cultura do cuidado popular torna-se uma ferramenta de sobrevivência das famílias no contexto que as rodeia, por meio de tradições e costumes".

Diante desses contextos, a solidariedade apresenta-se como um aspecto significativo das práticas de cuidado. Na história de vida das parteiras tradicionais, por exemplo, Dias ${ }^{14}$ ressalta que estas passaram a desenvolver o oficio por solidariedade, em resposta à demanda das parturientes da família e da comunidade. Tanto as práticas das parteiras, quanto as demais práticas são oferecidas às pessoas da família e à comunidade, constituindo-se em redes de apoio social. Nessa rede, também é possível receber auxílio para acessar os serviços públicos de saúde $14,16,18,20,24,27,28$.

Nessa mesma perspectiva, Rückert et al. ${ }^{15}$ salientam a importância do apoio social desenvolvido pelos movimentos sociais, em especial o MST, no fortalecimento da autoestima e da autonomia das pessoas com sofrimento mental e/ou uso prejudicial de álcool e outras drogas. Por esse motivo, o MST foi apontado como um movimento social que promove processos de formação e emancipação humana.

Diante do exposto, pode-se afirmar que a população camponesa vivencia situações-limites ${ }^{34} \mathrm{em}$ decorrência das condições de vida e saúde no campo brasileiro e encontra, nas práticas de cuidado em saúde, uma forma de incidência nessa realidade concreta. Uma vez que não são as situações-limites por si só que promovem a falta de esperança, mas sim a percepção delas como algo insuperável, a partir do momento em que os camponeses passam a perceber a realidade de forma crítica, dedicam-se à superação dessas situações-limites e à construção do inédito viável.

Ainda nessa perspectiva, destaca-se a dimensão normativa da vida, na qual o ser humano é um ser que busca sempre estabelecer novos valores no meio. Saúde, para Canguilhem ${ }^{32}$, não é apenas se adaptar às exigências do meio, mas é também ser normativo, é abusar do meio e poder tornarse doente. Nessa dimensão, a saúde expressa segurança, uma vez que representa uma maneira de "abordar a existência com uma sensação não apenas de possuidor ou portador, mas também, se necessário, de criador de valor, de instaurador de normas vitais" 32 (p. 152).

\section{A produção e mobilização dos saberes de cuidado em saúde da população do campo}

Ao estudarmos as dinâmicas de produção e mobilização dos saberes do cuidado em saúde da população do campo, deparamo-nos com uma série de aspectos que integram essa dinâmica, que incluem a aprendizagem familiar e com antepassados, o acesso a saberes disciplinares, a observação, a experimentação e a socialização de saberes em grupos de mulheres e em movimentos sociais, passando, inclusive, pelas diversas experiências de vida.

Entre as formas de socialização dos saberes de cuidado, a familiar foi a mais citada pelos autores ${ }^{14,18,20,24,25,27}$. Em alguns casos, é possível encontrar até três gerações de uma mesma família desenvolvendo práticas de cuidado concomitantemente ${ }^{24}$. Para além do núcleo familiar, a socialização de saberes entre gerações também foi evidenciada pela literatura ${ }^{19,20,25,28,29}$. Por outro lado, pode-se constatar a perda de interesse entre as gerações mais jovens no aprendizado de práticas culturais de saúde ${ }^{21}$. 
Considerando-se o acesso aos saberes disciplinares, ressalta-se o aprendizado a partir de livros, revistas e programas de televisão que abordam assuntos de saúde ${ }^{20}$ e a participação em $\operatorname{cursos}^{19,20,22,24}$. Alguns dos conhecimentos que circulam no âmbito do cuidado são provenientes do sistema convencional de saúde e, geralmente, são apresentados pelos profissionais em circunstâncias de cuidado de si ou de familiares ${ }^{20,24,28}$.

Teixeira e Oliveira ${ }^{20}$ relatam o processo de formação de uma cuidadora assentada, no qual se reconhece a importância dos cursos, assim como a consolidação desses conhecimentos no dia a dia dos trabalhos de cuidado com as demais famílias. Nessa mesma perspectiva, o papel da experiência na produção dos saberes de cuidado foi ressaltado por Silveira et al. ${ }^{28}$, Zilmer et al. ${ }^{18}$ e Wunsch et al. ${ }^{19}$. De acordo com esses autores, as práticas de cuidado ancoram-se em inúmeros conhecimentos originados nas mais diversas experiências de vida.

Ainda de acordo com Teixeira e Oliveira ${ }^{20}$, para sentirem-se confiantes com as escolhas realizadas nas práticas de cuidado, as mulheres assentadas lançam mão de inúmeras fontes de saberes, aderindo às que consideram mais apropriadas às especificidades de cada pessoa. Ricardo e Stotz ${ }^{23}$ ressaltam que a observação e a experimentação são fundamentais na produção dos saberes de cuidado, e o alcance de resultados exitosos é primordial para o seguimento da escolha terapêutica.

A esse respeito, Freire $^{34}$ defende a articulação entre a teoria e a prática em uma unidade indissolúvel, ou seja, na práxis, na construção de um conhecimento crítico e de uma ação transformadora sobre a realidade. De acordo com Freire e Nogueira ${ }^{35}$ : "[...] o conhecimento mais sistematizado é indispensável à luta popular [...], mas esse conhecimento deve percorrer os caminhos da prática"35. (p. 25)

No estudo de Cavalcante e Nogueira ${ }^{22}$, é possível constatar o papel do MST na socialização e produção dos saberes de cuidado, seja a partir das capacitações e cursos construídos pelo movimento, seja a partir da sua própria organização, que impulsiona o desenvolvimento das práticas coletivas de saúde.

Outra forma de socialização dos saberes de cuidado destacada pela literatura são os grupos de mulheres. Nesses espaços, elas compartilham informações acerca das práticas de cuidado, conversam sobre assuntos relacionados à saúde e realizam oficinas de preparo de remédios caseiros. Dessa forma, os grupos proporcionam maior segurança das mulheres perante suas escolhas terapêuticas ${ }^{20,24,25}$, além de atuarem como espaços de companheirismo, diálogo e formação de cidadania e autoestima ${ }^{20,26}$. Trata-se de um processo pedagógico que "tanto encanta quanto possibilita a criatividade e o prazer na busca de ser mais gente" 26 (p. 586). Além disso, proporciona maior visibilidade do trabalho feminino de cuidados perante a comunidade ${ }^{24}$.

Pulga ${ }^{26}$ reconhece as experiências dos grupos de mulheres como um processo educativoterapêutico, uma vez que:

[...] trazem a visibilidade de setores excluídos e os incluem de forma organizada; trazem novas formas de se organizar e de exercício do poder; trazem novos conteúdos e novas metodologias [...]. Essas experiências que as mulheres vivenciam trazem como elementos pedagógicos o processo educativo como um todo, e não apenas atos isolados, a participação ativa, a capacidade de ouvir, de fazer, de construir juntos, de enfrentar conflitos e contradições ${ }^{26}$. ( $p$. 585)

Assim sendo, tais experiências nos mostram possibilidades de formação dos trabalhadores do campo a partir de uma "perspectiva transformadora, integral do ser humano, emancipatória e produtora de cidadania" 26 (p. 583) e nos lembram que homens e mulheres "se educam em comunhão, mediatizados pelo mundo" 34 (p. 69). 


\section{Considerações finais}

Este estudo, por meio de revisão integrativa da literatura, abordou os saberes e as práticas de cuidado em saúde adotadas pela população do campo em território brasileiro. A análise da literatura evidenciou uma diversidade cultural nas práticas de cuidado, que envolvem o uso de plantas medicinais, crenças e religiosidade, alimentação saudável, apoio social, ações de prevenção, entre outras. Tais práticas, geralmente, vêm acompanhadas de um momento de diálogo e companheirismo, que possibilitam a construção de um olhar crítico sobre o processo saúde-doença e ocorrem de forma integrada entre si.

Verificou-se que o contexto cultural e a dificuldade econômica e de acesso aos serviços de saúde favorecem o desenvolvimento das práticas de cuidado em saúde. Estas são marcadas por um cuidado humanizado, por uma relação de respeito à natureza, por uma concepção holística de saúde e pela solidariedade. Seu desenvolvimento ancora-se em inúmeros saberes, que têm origem na aprendizagem familiar e com antepassados, no acesso a saberes disciplinares, na socialização de saberes nos grupos de mulheres e no movimento social, bem como nas experiências diversas de vida. Esses grupos, por sua vez, foram reconhecidos como um processo pedagógico, que trazem importantes contribuições aos processos de formação humana dos trabalhadores do campo.

Constata-se a necessidade de maior valorização dos saberes de cuidado, bem como a integração destes com os saberes do sistema convencional de saúde. Para tanto, faz-se necessário investir no desenvolvimento de ações de educação popular em saúde com a população do campo, bem como ações de educação permanente em saúde com os trabalhadores do SUS.

Além disso, este estudo reforça a importância da consolidação da Política Nacional de Saúde Integral das Populações do Campo, da Floresta e das Águas, uma vez que tal proposta congrega essas e outras reflexões sobre a saúde do campo. Reforça-se, também, a necessidade de se criar estratégias de efetivação da Política Nacional de Plantas Medicinais e Medicamentos Fitoterápicos, pois tais práticas, mais uma vez, mostraram-se de grande aceitação por parte da população do campo.

Por fim, considerando-se a relevância do tema em questão, destacamos a necessidade de novos estudos que aprofundem os aspectos socioculturais das práticas de cuidados da população do campo e a relação entre essas práticas, os processos de trabalho na agricultura e o modelo de desenvolvimento no campo brasileiro.

\section{Colaboradores}

Bianca Rückert trabalhou no levantamento e análise dos dados e na concepção, redação e revisão do artigo. Daisy Moreira Cunha participou da revisão e da aprovação da versão final do artigo. Celina Maria Modena foi responsável pela orientação da pesquisa e participou da revisão e da aprovação da versão final do artigo.

\section{Agradecimentos}

Agradecemos ao Instituto René Rachou (IRR-Fiocruz) pelo auxílio financeiro e à Coordenação de Aperfeiçoamento de Pessoal de Nível Superior (Capes) pela concessão de bolsa de doutorado. 


\section{Referências}

1. Ministério de Planejamento, Orçamento e Gestão (BR). Instituto Brasileiro de Geografia e Estatística. Vamos conhecer o Brasil. Nosso povo. Características da população [internet]. 2017 [citado 04 Abr 2017]. Disponível em: http://7a12.ibge.gov.br/vamos-conhecer-obrasil/nosso-povo/caracteristicas-da-populacao.html.

2. Ministério de Planejamento, Orçamento e Gestão (BR). Instituto Brasileiro de Geografia e Estatística. Sinopse preliminar do censo demográfico 2000. [internet]. 2000 [citado 04 abr 2017]. Disponível em: https://www.ibge.gov.br/home/estatistica/populacao/sinopse preliminar/Censo2000sinopse.pdf.

3. Bezerra ML, Bacelar T. As concepções contemporâneas de ruralidade e suas singularidades no Brasil. In: Miranda $\mathrm{C}$, Silva $\mathrm{H}$, organizadores. Concepções da ruralidade contemporânea: as singularidades brasileiras. Brasília: IICA; 2013. p. 35-75.

4. Ministério da Saúde (BR). Secretaria de Gestão Estratégica e Participativa. Departamento de Apoio à Gestão Participativa. Política Nacional de Saúde Integral das Populações do Campo e da Floresta. Brasília (DF): MS; 2013

5. Silva FCCM, Gonçalves JWS, Santorum JA, Souto KMB, Souza MS, Pessoa VM. Saúde integral das populações do campo, da floresta e das águas. Fortaleza: Universidade Federal do Ceará; 2017.

6. Ministério da Saúde (BR). Plano Nacional de Saúde: um pacto pela saúde no Brasil. Brasília (DF): MS; 2004

7. Ministério da Saúde (BR). Secretaria-Executiva. Subsecretaria de Planejamento e Orçamento. Plano Nacional de Saúde - PNS: 2012-2015. Brasília (DF): MS; 2011.

8. Ministério da Saúde (BR). Secretaria de Gestão Estratégica e Participativa. Plano Operativo de Saúde das populações do campo e da floresta 2012/2015. Brasília (DF): MS; 2011.

9. Carneiro FF, Burigo AC, Dias AP. Saúde no campo. In: Caldart RS, Pereira IB, Alentejano P, Frigotto G, organizadores. Dicionário da Educação do Campo. Rio de Janeiro: EPSJV; São Paulo: Expressão Popular; 2012. p. 696-9.

10. Ministério da Saúde (BR). Secretaria de Gestão Estratégica e Participativa. Departamento de Apoio a Gestão Participativa. Política Nacional de Educação Popular em Saúde. Brasília (DF): MS; 2012.

11. Vasconcelos EM. Para além do controle social: a insistência dos movimentos sociais em investir na redefinição das práticas de saúde. In: Fleury S, Lobato LVC, organizadoras. Participação, Democracia e Saúde. Rio de Janeiro: Cebes; 2009. p. 270-88.

12. Mendes KDS, Silveira RCCP, Galvão CM. Revisão integrativa: método de pesquisa para a incorporação de evidências na saúde e na enfermagem. Texto Contexto Enferm. 2008; 17(4):758-64.

13. Souza MT, Silva MD, Carvalho R. Revisão integrativa: o que é e como fazer. Einstein. 2010; 8(1):102-6.

14. Dias MD. Histórias de vida: as parteiras tradicionais e o nascimento em casa. Rev Eletr Enferm. 2007; 9(2):479-88

15. Rückert B, Machado AR, Santos CCA, Brito PCD. Diálogos entre a Saúde do Campo e a Saúde Mental: a experiência da Oficina de Educação Popular em Saúde Mental do MST na ESP MG. Interface (Botucatu). 2014; 18(2):1537-46.

16. Silva VHF, Dimenstein $M$, Leite JF. O cuidado em saúde mental em zonas rurais. Mental. 2013; 10(19):267-85.

17. Villela MM, Pimenta DN, Lamounier PA, Dias JCP. Avaliação de conhecimentos e práticas que adultos e crianças têm acerca da doença de Chagas e seus vetores em região endêmica de Minas Gerais, Brasil. Cad Saude Publica. 2009; 25(8):1701-10. 
18. Zilmer JGV, Schwartz E, Muniz RM. O olhar da enfermagem sobre as práticas de cuidado de famílias rurais à pessoa com câncer. Rev Esc Enferm. 2012; 46(6):1371-8.

19. Wusch S, Budó MLD, Beuter M, Garcia RP, Seiffert MA. Proteção: dimensão do cuidado em famílias rurais assentadas. Esc Anna Nery Rev Enferm. 2018; 18(3):533-8.

20. Teixeira IMC, Oliveira MW. Práticas de cuidado à saúde de mulheres camponesas. Interface (Botucatu). 2014; 18(2):1341-54.

21. Fita DS, Costa-Neto EM, Schiavetti A. "Offensive" snakes: cultural beliefs and practices related to snakebites in a Brazilian rural settlement. J Ethnobiol Ethnomed. 2010; 6(13):1-13.

22. Cavalcante IMS, Nogueira LMV. Práticas sociais coletivas para a saúde no Assentamento Mártires de abril na Ilha de Mosqueiro. Esc Anna Nery Rev Enferm. 2008; $12(3): 492-9$.

23. Ricardo LM, Stotz EN. Educação Popular como método de análise: relações entre medicina popular e 'situação-limite' vivenciada por trabalhadores do Movimento dos Trabalhadores Rurais Sem-Terra. Rev APS. 2012; 15(4):435-42.

24. Lima ARA, Heck RM, Vasconcelos MKP, Barbieri RL. Ações de mulheres agricultoras no cuidado familiar: uso de plantas medicinais no sul do Brasil. Texto Contexto Enferm. 2014; 23(2):365-72.

25. Thum MA, Ceolin T, Borges AM, Heck RM. Saberes relacionados ao autocuidado entre mulheres da área rural do sul do Brasil. Rev Gaúcha Enferm (Online). 2011; 32(3):576-82.

26. Pulga VL. Contribuições do Movimento de Mulheres Camponesas para a formação em saúde. Trab Educ Saude. 2013; 11(3):573-90.

27. Santos RC, Silva MS. Condições de vida e itinerários terapêuticos de quilombolas de Goiás. Saude Soc. 2014; 23(3):1049-63.

28. Silveira CL, Budó MLD, Ressel LB, Oliveira SG, Simon BS. Apoio Social como possibilidade de sobrevivência: percepção de cuidadores familiares em uma comunidade remanescente de quilombos. Cienc Cuid Saude. 2011; 10(3):585-92.

29. Almeida CFCBR, Ramosa MA, Amorim ELC, Albuquerque UP. A comparison of knowledge about medicinal plants for three rural communities in the semi-arid region of northeast of Brazil. J Ethnopharmacol. 2010; 127:674-84.

30. Pinheiro R. Cuidado em saúde. In: Pereira IB, França Lima JC, organizadores. Dicionário de Educação Profissional em Saúde. 2a ed. Rio de Janeiro: EPSJV; 2009. p. 110-4.

31. Ayres JRCM. Cuidado e reconstrução das práticas de saúde. Interface (Botucatu). 2004; $8(14): 73-92$.

32. Canguilhem G. O normal e o patológico. Rio de Janeiro: Forense Universitária; 2009.

33. Canguilhem G. Escritos sobre a Medicina. Rio de Janeiro: Forense Universitária; 2005.

34. Freire P. Pedagogia do Oprimido. 17a ed. Rio de Janeiro: Paz e Terra; 1987.

35. Freire P, Nogueira A. Que fazer: teoria e prática em educação popular. 10a ed. Petrópolis: Vozes; 2009. 
Rückert B, Cunha DM, Modena CM. Saberes y prácticas de cuidado en salud de la población del campo: revisión integradora de la literatura. Interface (Botucatu). 2018; 22(66):903-14.

Este artículo presenta los resultados de una revisión integradora de literatura sobre los saberes y las prácticas de cuidado en salud de la población del campo en el territorio brasileño. Se analizaron 16 artículos, a partir de una selección en las bases de datos BVS, Scielo y Observatório da Política Nacional de Saúde Integral das Populações do Campo, Floresta e Águas (OBTEIA), sin recorte temporal. El análisis de la literatura dejó en evidencia la diversidad de las prácticas de cuidado que envuelven plantas medicinales, creencias y religiosidad, alimentación saludable, apoyo social, prevención y otras más. Se verificó que el contexto cultural y la dificultad económica y de acceso a los servicios de salud favorecen el desarrollo de esas prácticas y que ellas se basan en innumerables saberes. Se subraya la necesidad de una mayor valorización de esos saberes, así como su integración con los del sistema convencional de salud.

Palabras clave: Conocimientos, actitudes y práctica en salud. Cuidado en salud. Saberes. Salud de la población rural. Revisión de la literatura.

Submetido em 15/08/17. Aprovado em 29/09/17. 